\title{
ANÁLISE DO SISTEMA DE MEDIÇÃO DE DESEMPENHO DE UMA ORGANIZAÇÃO AGROINDUSTRIAL
}

\section{ANALYSIS OF THE PERFORMANCE MEASUREMENT SYSTEM OF AN AGRO- INDUSTRIAL ORGANIZATION}

\author{
Livia Nicoli Berti \\ Lesley Carina do Lago Attadia Galli ${ }^{\mathrm{II}}$ \\ Cristiane Sonia Arroyo ${ }^{\text {III }}$ \\ Glaucia Aparecida Prates ${ }^{\mathrm{IV}}$ \\ Sheila Farias Alves Garciav
}

\begin{abstract}
RESUMO
O objetivo deste trabalho foi identificar os elementos críticos no sistema de medição de desempenho (SMD) em uma organização agroindustrial. Uma pesquisa descritiva foi realizada com abordagem qualitativa utilizando como método uma pesquisa em campo em uma empresa do setor agroindustrial na cidade de Jaboticabal-SP. Como resultado obteve-se um maior entendimento do SMD utilizado na empresa. Os resultados mostram que há uma utilização parcial dos indicadores do SMD, pois o sistema é limitado e restrito apenas aos indicadores impostos pelo Sistema de Gestão da Qualidade (SGQ) e atendimento das normas da ISO 9001:2008, portanto, esse fato deixa de trazer benefícios para a empresa porque o SMD não é usado pelos gestores como uma visão e tomada de decisão estratégica. Sugere-se para que todo esse processo seja eficiente e eficaz, as etapas do SMD tais como desenvolvimento, implantação, uso, além da comunicação dos indicadores devem ser trabalhadas em toda sua extensão com uma visão estratégica entre os gestores e colaboradores com a finalidade de contribuir para o desenvolvimento da organização.
\end{abstract}

Palavras-chave: Sistema. Medição. Desempenho. Indicadores. ISO 9001:2008.

\begin{abstract}
The objective of this work was to identify the critical elements in the performance measurement system (SMD) in an agro-industrial organization. A descriptive research was carried out with a qualitative approach using as a method a field research in a company in the agroindustrial sector in the city of Jaboticabal-SP. As a result, a greater understanding of the SMD used in the company was obtained. The results show that there is a partial use of The

\footnotetext{
I Mestre em Administração pela UNESP, CEPECAF - UNESP - São Paulo - Brasil. E-mail: Livia Nicioli Berti.

II Doutora em Administração pela FEA USP. Docente e Pesquisadora da Faculdade de Ciências Agrárias e Veterinárias - UNESP - Jaboticabal - São Paulo. E-mail: lesley.attadia@unesp.br.

III Doutora em Administração pela FEA USP. Pesquisadora do PAPO: grupo de pesquisa do Programa de Apoio a Produção e Operações da FEARP USP - São Paulo - Brasil e do CEPECAF - UNESP - São Paulo - Brasil. Email: csarroyo@terra.com.br.

IV Doutora em Engenharia de Produção pela UFSC. Docente da Faculdade de Ciências Agrárias e Veterinárias UNESP - Jaboticabal - São Paulo - Brasil. E-mail: g.prates@unesp.br.

v Doutora em Administração FEA USP. Docente e Pesquisadora da Faculdade de Ciências Agrárias e Veterinárias - UNESP - Jaboticabal - São Paulo. E-mail: sheila.gracia@unesp.br.
} 


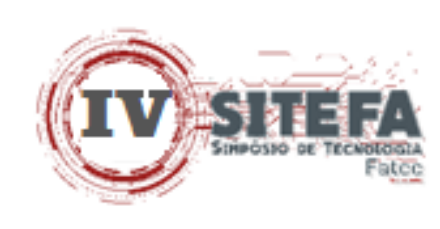

MDS indicators because the system is limited and restricted only to the indicators imposed by the Quality Management System (QMS) and compliance with ISO 9001:2008 standards, therefore, this fact ceases to bring benefits to the company because in the SMD it is not used by managers as a vision and strategic decision-making. It is suggested that this whole process is efficient and effective, the stages of The MDS such as development, implementation, use, in addition to the communication of indicators should be worked in their entirety with a strategic vision among managers and employees in order to contribute to the development of the organization.

Keywords: System. Measurement. Performance. Indicators. ISO 9001:2008.

Data de submissão do artigo: 30/06/2021.

Data de aprovação do artigo: 15/09/2021.

DOI: $10.33635 /$ sitefa.v4i1.191

\section{INTRODUÇÃO}

A medição de desempenho passou a ser um desafio para muitas organizações. Miura, Kobayashi e Shirasaka (2020) relatam que a gestão de indicadores de desempenho exerce um papel fundamental na organização, pois auxilia na tomada de decisão à medida que constrói estratégias, implanta dentro da organização uma cultura de medição que traz pagamento de recompensas e avalia o impacto no desempenho global da empresa de acordo com os objetivos atingidos.

Deste modo, criar uma cultura de medição de desempenho é necessária para que mostre para a organização a oportunidade de melhoria. Isso porque o sistema de medição de desempenho (SMD) seja reconhecido, muitas organizações falham no desenvolvimento ou na implantação do método escolhido. Os gestores consideravam apenas indicadores financeiros para registrar os investimentos no balanço das empresas; contudo, atualmente, os ativos intangíveis passaram a ter maior importância, e são uma fonte de vantagem competitiva. Assim, a criação de valor passou a ser baseada no conhecimento, o que é diretamente ligado a avaliação de desempenho em uma empresa (SANTOS, 2020).

Dentro deste contexto, este trabalho apresenta o seguinte problema de pesquisa: quais são os elementos críticos, fatores facilitadores e restritivos, no processo de desenvolvimento, implantação e uso dos sistemas de medição de desempenho (SMD)?

Partindo da questão de pesquisa descrita, este trabalho tem o objetivo geral de analisar os SMD que são compostos por processos de desenvolvimento, implantação e uso de uma empresa do setor agroindustrial, identificando os elementos críticos que são os fatores facilitadores e restritivos.

O Agronegócio tem sido desde o início do processo de modernização e industrialização da produção agropecuária do país, objeto de diversos estudos e debates. De acordo com a Associação Brasileira do Agronegócio (2021), a agropecuária foi a único setor com variação positiva no ano passado, com $(2,0 \%)$ e diferente do contexto indústria $(-3,5 \%)$ e serviços $(-4,5 \%)$. Considerada essencial para o funcionamento das cadeias de alimentos, desde a produção até a entrega ao consumidor final, a agropecuária não parou pandemia. A safra colhida em 2020 obteve quantidade recorde no café e nos grãos, com o bom desempenho das culturas de soja e milho (ABAG, 2021). 


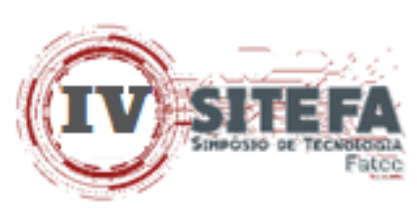

\section{SISTEMAS DE MEDIÇÃO DE DESEMPENHO (SMD)}

Os sistemas de medição podem ser definidos como um conjunto de medidas integradas, em diferentes níveis de agregação, sendo associados a programas de melhoria em desenvolvimento (OLIVEIRA; LANTELME; FORMOSO, 1995). O sistema de medição de desempenho (SMD) começa a ser definido a partir da missão da organização e das estratégias relacionadas com essa missão, por meio da identificação dos fatores críticos de sucesso do negócio, que são alvos de melhorias para o Prêmio Nacional da Qualidade da Fundação Nacional de Qualidade (FNQ, 2012).

Medidas isoladas não são capazes de fornecer informações suficientes para a tomada de decisão (OLIVEIRA; LANTELME; FORMOSO, 1995) Em uma visão mais técnica, Kueng, Meier e Wettstein (2000) alegam que o SMD pode ser definido como um sistema de tecnologia de informação (TI) que coleta dados relevantes de desempenho a partir de várias fontes, compara dados recentes com dados históricos e metas, e comunica os resultados para os usuários.

Quadro 01 - Etapas dos sistemas de medição de desempenho (SMD)

\begin{tabular}{|l|l|}
\hline $\begin{array}{l}\text { ETAPAS DOS } \\
\text { SMD }\end{array}$ & DESCRIÇÃO DOS SMD \\
\hline $\begin{array}{l}\text { Definição de } \\
\text { indicadores de } \\
\text { desempenho }\end{array}$ & $\begin{array}{l}\text { Elementos fundamentais para medir o desempenho, bem como para a } \\
\text { definição das variáveis que melhor representam o desempenho geral das } \\
\text { organizações por Callado e Andrade (2008) e Mitchell (2004). }\end{array}$ \\
\hline \multirow{5}{*}{$\begin{array}{l}\text { Desenvolvimento e Austin (2002) citam como primeiros passos para a criação de } \\
\text { um SMD: a. Definir a missão da empresa; b. Identificar os objetivos } \\
\text { estratégicos em relação a lucratividade, participação de mercado, } \\
\text { qualidade, custo, flexibilidade e inovação; c. Desenvolver os objetivos } \\
\text { das áreas funcionais em relação às estratégicas; d. Criar, para cada área } \\
\text { funcional, medidas de desempenho capazes de definir a competitividade } \\
\text { da empresa em nível operacional; e. Comunicar os objetivos } \\
\text { estratégicos e as respectivas medidas de desempenho para todos os } \\
\text { níveis hierárquicos; f. Assegurar a consistência entre os objetivos } \\
\text { estratégicos por meio do sistema de medição de desempenho; g. Usar } \\
\text { feedback do SMD para identificar os pontos fracos organizacionais, } \\
\text { melhorando o posicionamento competitivo; e h. Reavaliar } \\
\text { periodicamente a eficácia do SMD em relação aos objetivos estratégicos } \\
\text { conforme Attadia e Martins (2003) e Neely e Austin (2002). }\end{array}$} \\
\hline $\begin{array}{l}\text { Organizações fazem projetos de design, implementando medidas para } \\
\text { melhoria de desempenho, pouca consideração é dada ao modo como } \\
\text { estas medidas evoluem após a sua implementação. Os SMD são } \\
\text { dinâmicos e devem continuar a refletir as questões de importância para } \\
\text { o negócio por Kennerley, Neely e Adams (2003). }\end{array}$ \\
\hline $\begin{array}{l}\text { Os indicadores de desempenho precisam atender critérios como } \\
\text { seletividade ou importância, simplicidade e clareza, abrangência, } \\
\text { rastreabilidade e acessibilidade, comparabilidade, estabilidade e rapidez } \\
\text { de disponibilidade e baixo custo de obtenção (FERNANDES, 2004). }\end{array}$ \\
\hline
\end{tabular}

Fonte: Elaborado pelos autores (2021) 


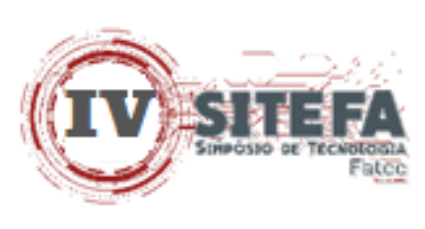

\section{METODOLOGIA DA PESQUISA}

Este trabalho é uma pesquisa aplicada (SALOMON, 1991), de caráter descritivo (FACHIN, 2006) e abordagem qualitativa (COOPER; SCHINDLER, 2003). Uma pesquisa descritiva foi realizada com abordagem qualitativa utilizando como método uma pesquisa em campo em uma empresa do setor agroindustrial na cidade de Jaboticabal-SP.

A coleta de dados foi elaborada através de entrevistas por videoconferência realizadas no ano de 2020.

Essas técnicas de pesquisa foram aplicadas de forma individual e pessoalmente com cada gestor da empresa responsável pelas áreas: financeira, logística, recursos humanos e produção. Assim, foi possível identificar a opinião sobre o sistema de medição de desempenho, indicadores, sistema de gestão de qualidade na agroindústria.

\section{RESULTADOS E DISCUSSÃO}

O Agronegócio tem sido desde o início do processo de modernização e industrialização da produção agropecuária do país, objeto de diversos estudos e debates. De acordo com a Associação Brasileira do Agronegócio (ABAG, 2017), pode-se destacar um conjunto de produtos agrícolas que vem puxando o crescimento da agropecuária brasileira, tais como algodão, arroz, cana-de-açúcar, laranja, mandioca, milho, soja e uva.

Tivemos uma queda na safra de grãos 2016/17, predominantemente pelo fator clima, onde recuamos para cerca de 190 milhões de toneladas. Porém, as perspectivas da nova safra, 2017/2018 apontam para uma supersafra, acima de 213 milhões de toneladas de grãos.

Portanto, o Brasil é grande no agronegócio, o $4^{\circ}$ maior exportador mundial quando incluímos toda a visão das cadeias produtivas com o pós-porteira das fazendas, onde despontam Estados Unidos, Holanda, Alemanha e Brasil e o $2^{\circ}$ maior quando não computamos a transformação e ad value, fortíssimas presenças em Holanda e Alemanha.

A Agroindústria faz parte do agronegócio, sendo o setor que transforma ou processa matérias primas agropecuárias em produtos elaborados, adicionando valor ao produto.

Segundo dados da Embrapa a agroindústria tem participação de aproximadamente 5,9\% no Produto Interno Bruto (PIB) brasileiro, no beneficiamento, na transformação dos produtos e no processamento de matérias-primas provenientes da agropecuária, promovendo dessa forma maior integração do meio rural com a economia de mercado.

\subsection{Caracterização da empresa foco do estudo}

A empresa em questão é a única que trabalha com o diferencial do cobre em sua formulação, tornando-se referência no mercado de defensivos e fertilizantes. A empresa base do estudo atua na fabricação de defensivos agrícolas e fertilizantes. Os produtos da empresa se dividem, segundo a sua utilidade, em três grupos: nutrição de plantas que são os fertilizantes, proteção de plantas ou defensivos agrícolas e lavagem de equipamentos que são elaborados para limpeza e descontaminação de equipamentos agrícolas (máquinas, pulverizadores, entre outros).

Para efeitos de estrutura de linhas da empresa, os produtos são divididos em Linha de: Proteção, Nutrição, Tecnologia em Aplicação e Óleos Emulsionáveis.

Os produtos voltados para a nutrição apresentam micronutrientes que ajudam a cultura se desenvolver, como aumenta o enraizamento das plantas, melhora desenvolvimento, 


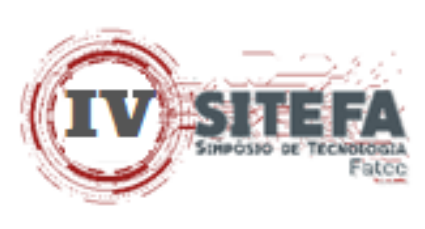

aumenta a resistência das plantas com mudanças climáticas e diminuem o risco de queda de folhas entre outros vários benéficos de fertilizantes.

A linha de Tecnologia são produtos que ajudam na produção do produtor rural, nos quais tem o objetivo de melhorar a pulverização, agindo de forma com que na pulverização haja um maior fornecimento de nitrogênio e fosforo e facilitar a pulverização com maior número de gotas.

Por último, óleos emulsionáveis tratados como uma linha pois são feitos a partir de óleo vegetal e mineral com o objetivo de ajudar a penetração e fixação dos outros produtos.

\subsection{Desenvolvimento do sistema de medição de desempenho (SMD)}

A empresa possui um Sistema de Gestão da Qualidade (SGQ), criado no ano de 2008, para a obtenção da certificação ISO 9001:2008. A busca por essa certificação ocorreu devido à tendência do mercado em dar preferência às empresas que tenham certificações.

O SGQ exige uma documentação cuja estrutura apresenta alguns pontos necessários para sua implementação, que são a necessidade de medição, monitoramento e análise dos processos. Para medir, monitorar e analisar os processos, é preciso estabelecer alguns métodos e padrões de medição do sistema produtivo e da fábrica.

O método escolhido pela empresa foi à criação de indicadores de desempenho, que se inter-relacionam, configurando um sistema de medição de desempenho (SMD). Desta maneira, após a criação do SGQ, a empresa adotou um SMD, medido através de indicadores de desempenho específicos, sendo um método de extrema importância para a empresa, visto que através dos indicadores é possível observar a situação de cada setor e/ou processo dela, e através deles elaborar um sistema de análise, abordando a empresa como um todo.

\subsection{A implantação do sistema de medição de desempenho (SMD)}

A implantação teve todo apoio da diretoria, que era informada por meio de reuniões de todo andamento do processo, das dificuldades e conquistas e ajudava nos ajustes que tinham que ser feitos. Esta etapa teve auxílio da consultoria, por ser algo novo e ter muitos detalhes a serem ajustados. Os coordenadores e funcionários começaram a se envolver apenas quando o sistema já estava pronto, e com seus indicadores definidos.

Por ser algo novo, a principal dificuldade foi à adaptação por parte dos gerentes em entender a importância disso para empresa.

A apresentação foi feita pela coordenadora do SGQ, que mostrou a importância que esses indicadores teriam para a empresa, principalmente como seriam fundamentais em relação à busca pela certificação da ISO 9001:2008. Primeiro essa apresentação foi para diretoria e gerentes, e estes passaram para sua equipe. Não tendo inicialmente nenhum tipo de resistência por parte de diretores, coordenadores e colaboradores envolvidos.

A realização de uma reunião semanal entre os líderes, e uma reunião semanal dos líderes com seu setor é uma forma de intensificar a comunicação e promover a participação de todos os funcionários participarem desse processo.

Do ponto de vista dos diretores da empresa entre as vantagens que o SMD traz para a empresa estão à facilidade para estabelecer as metas e compará-las com as informações realizadas, identificando pontos fortes e fracos da empresa, permitindo avaliar melhor o desempenho da empresa e sua competitividade no mercado. Além de auxiliar na busca pela melhoria contínua e por meio desta alcançar a certificação da ISO 9001:2008. 


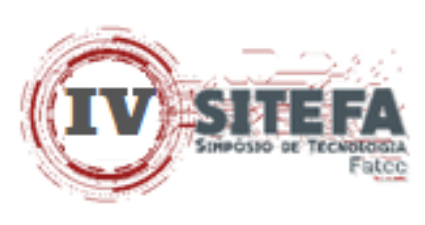

Entre os indicadores mais utilizados pela diretoria está o indicador da Qualidade que mede a eficácia do SGQ, e que avalia todos os indicadores para que se atinja a melhoria contínua e a auxilie na certificação da ISO 9001:2008.

Em relação aos pontos de melhoria do SMD, a diretoria afirma que é imprescindível que a empresa busque o desenvolvimento e aprofunde seu SMD, readequando as medidas e os objetivos, incorporando e aplicando, com mais eficácia.

A empresa não possui um SMD definido abrangendo todos os indicadores. Estes são avaliados de forma individual e somente quando necessário, em conjunto. A viabilização de um SMD é necessária para que se possa enxergar o sistema de desempenho como um só, integrando os indicadores e avaliando a importância deles para o crescimento da empresa. Para auxiliar esse processo a empresa pode se utilizar de um quadro com os atributos dos indicadores de desempenho, tornando o sistema visual e transparente a toda organização. Em contrapartida, como ponto positivo destaca a eficiência do sistema que facilita os coordenadores na tomada de decisão e a atingir a melhoria contínua e o desenvolvimento da empresa.

Ressalta ainda, que como melhoria é preciso que o sistema seja bem estruturado, que todas as pessoas estejam envolvidas, e que estas tenham a absoluta consciência que o resultado não virá apenas com o uso do SMD e o bom desempenho de seus indicadores, mas com o bom alinhamento estratégico desse sistema e o comprometimento de todos na busca pela excelência.

Através da entrevista foi observado que a maioria dos coordenadores liga diretamente a importância desses indicadores à certificação da ISO 9001:2008, não vendo nenhuma outra vantagem neles. Muitos apenas passam os dados solicitados, e só se preocupam quando ficam abaixo das médias. Evidencia-se que não se dá a real importância ao sistema de indicadores nas empresas, apesar de a medição ser um dos requisitos mais importantes de um SGQ para assegurar que os objetivos estejam sendo cumpridos, sejam eles para satisfação dos consumidores, controle da qualidade dos produtos e serviços, padronização de processos, iniciativas de melhoria ou de inovação.

O sistema fica centralizado nas mãos da coordenadora do SGQ, que fica responsável por colher os dados, fazer a análise e entregá-las prontas aos departamentos, que fazem a divulgação apenas entre eles. A forma de coleta de dados é pobre, limitado a uma única pessoa e não integrado ao sistema de gestão. Verifica-se que será necessário que se incorpore o uso da SMD para suportar a melhoria, o que é diferente para controlar e implementar da estratégia e das operações.

Como melhoria do sistema, vários coordenadores citam que haja integração entre os indicadores do sistema, permitindo o acesso de todos os colaboradores e não fícando centralizados apenas dentro de cada setor.

O sistema encontra-se deficiente, pois possui muitas falhas na sua comunicação, falta de divulgação de seus coordenadores para seus subordinados, a maioria dos funcionários da empresa nem sabem que existe esse sistema e muito menos da sua finalidade e importância para o desenvolvimento da empresa. Para os colaboradores que tem acesso, esses limitam sua finalidade para o alcance da certificação da ISO 9001:2008.

Embora ocorram reuniões para avaliação dos indicadores dos departamentos, elas acabam voltando-se para o foco da melhoria das metas desses indicadores. Ou seja, ainda não se pode dizer que há um SMD principalmente por falta de uma infraestrutura eficiente de suporte conforme estabelecido por Franco-Santos et al. (2007). Têm-se, portanto, um conjunto de medidas de desempenho que suportam melhorias contínuas, mas que estas não 


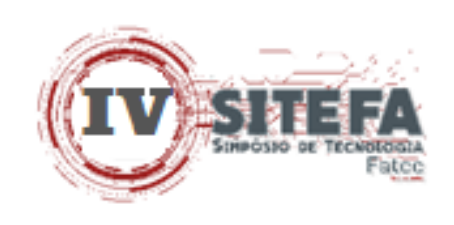

dependem totalmente destas medidas de desempenho para serem tomadas pela direção, estando, portanto, num estágio de melhoria contínua estruturada e coerente com o atual estágio da medição de desempenho.

\subsection{O uso do sistema de medição de desempenho (SMD)}

Semestralmente ocorre a reunião com a diretoria, onde todos os coordenadores e líderes da empresa apresentam seus indicadores e, juntos, discutem a melhor estratégia a ser tomada.

Além desta, mensalmente também ocorre outra reunião da qual participam os líderes e gestores dos setores de (Comercial, Manutenção, PCP, Compras, RH) juntamente com a coordenadora do SGQ. Durante a reunião, os números apresentados são discutidos e analisados por todos os integrantes, e aqueles que não atenderam à sua meta são debatidos de forma mais profunda, procurando descobrir a sua causa e elaborando um plano de ação de melhoria para aquele problema. E é também onde são discutidos problemas, propostas de melhoria, informes gerais e necessidades de treinamento.

A utilização de um SMD é benéfica para qualquer organização, pois serve como apoio para os gestores, que se utilizam dos indicadores e seus resultados como base para as tomadas de decisões, auxiliando no controle estratégico e contribuindo para o desenvolvimento e crescimento estrutural, operacional e organizacional da empresa. Porém o uso do SMD ainda se encontra restrito pelas áreas talvez pela falta de esclarecimento dos seus benefícios, mostrando o quanto ele pode ser utilizado de maneira estratégica e não só apenas como respostas para atendimentos dos indicadores solicitados pela ISO 9001:2008.

As áreas ficam limitadas, por falta de conhecimento junto com a falta de interesse em buscar algo melhor para o desenvolvimento da empresa. Talvez por comodidade e por achar que isso não agregará nada ao seu setor, e que respondendo as questões solicitadas pela análise dos indicadores eles estão favorecendo apenas ao setor do SGQ que é o responsável pelo SMD. Possuem uma visão restrita, seguindo o pensamento de que deve cuidar apenas do seu setor, não pensando na organização como um todo, limitando o desempenho do sistema.

As pessoas em uma organização devem ser responsabilizadas pelo desempenho geral, e não apenas focarem na qual são diretamente responsáveis conforme Gunasekaran, Patel e Tirtiroglu (2001). Sendo assim, o uso torna-se a maneira mais complexa para que a empresa obtenha resultados satisfatórios no SMD. Por falta de interesse, esclarecimentos ou até mesmo por uma imposição mais firme por parte da diretoria e SGQ.

Como alguns pontos de melhoria, temos a comunicação entre os diversos níveis hierárquicos que precisa ser intensificada. Somente os gestores e líderes possuem conhecimento sobre a situação e os indicadores da empresa. Dessa forma, a falta de informação deixa os funcionários confusos e sem saber com precisão qual seu papel dentro da organização e como ele deve executar seu serviço de forma que gere benefícios para ela.

Apesar de o certificado ISO 9001:2008 ampliar o mercado de atuação e assegurar a qualidade perante os clientes, a necessidade de medidas de desempenho iniciou-se apenas como necessidade de atendimento aos requisitos da norma. Vale observar que a maioria dos colaboradores pouco conhecia a abrangência e a necessidade de indicadores de desempenho, nem a estratégia, se existente, não era verbalizada e muito menos, comunicada. E a diretoria, sabe da sua importância, porém não retira o seu vínculo de restrição com a busca da melhoria contínua e atendimento das normas da ISO 9001:2008. 


\subsection{Indicadores de desempenho da empresa do setor agroindustrial}

Seguem os indicadores utilizados na organização, a sua descrição e interpretação.

Quadro 2 - Indicadores de desempenho usados no SMD

\begin{tabular}{|c|c|c|c|}
\hline $\begin{array}{c}\text { INDICADOR } \\
\text { DE } \\
\text { DESEMPENHO }\end{array}$ & DESCRIÇÃO & INTERPRETAÇÃO & $\begin{array}{l}\text { PRINCÍPIOS DO } \\
\text { SGQ DA ISO } \\
\text { 9001: } 2008\end{array}$ \\
\hline $\begin{array}{l}\mathrm{Rh}- \\
\text { treinamento }\end{array}$ & $\begin{array}{l}\text { Aumentar a } \\
\text { capacitação: } \\
\text { Meta de treinamentos } \\
\text { que devem ser dados no } \\
\text { ano x e a quantidade de } \\
\text { treinamentos realizados. }\end{array}$ & $\begin{array}{l}\text { Número de } \\
\text { treinamentos } \\
\text { programados / } \\
\text { Número de } \\
\text { treinamentos } \\
\text { realizados. }\end{array}$ & $\begin{array}{l}\text { Comprometimento } \\
\text { das pessoas. }\end{array}$ \\
\hline Rh - absenteísmo & $\begin{array}{l}\text { Aumentar o } \\
\text { comprometimento dos } \\
\text { colaboradores. }\end{array}$ & $\begin{array}{l}\text { Total de horas } \\
\text { trabalhadas / Total de } \\
\text { horas falta (atestados e } \\
\text { declarações de } \\
\text { ausência). }\end{array}$ & $\begin{array}{l}\text { Comprometimento } \\
\text { das pessoas. }\end{array}$ \\
\hline $\begin{array}{l}\text { Compras - } \\
\text { atraso na } \\
\text { entrega }\end{array}$ & $\begin{array}{l}\text { Atender a demanda } \\
\text { mediante programação. }\end{array}$ & $\begin{array}{l}\text { Média de dias de } \\
\text { atraso dos pedidos do } \\
\text { mês. }\end{array}$ & $\begin{array}{l}\text { Tomada de } \\
\text { decisões baseadas } \\
\text { em evidências. }\end{array}$ \\
\hline $\begin{array}{l}\text { Compras - } \\
\text { novos } \\
\text { fornecedores }\end{array}$ & $\begin{array}{l}\text { Atender a demanda } \\
\text { com maior número de } \\
\text { fornecedores } \\
\text { homologados. }\end{array}$ & $\begin{array}{l}\text { Quantidade de } \\
\text { fornecedores } \\
\text { homologados no ano. }\end{array}$ & $\begin{array}{l}\text { Gestão de } \\
\text { Relacionamentos. }\end{array}$ \\
\hline $\begin{array}{l}\text { Qualidade } \\
\text { Eficácia do SGQ }\end{array}$ & $\begin{array}{l}\text { Melhorar } \\
\text { continuamente a } \\
\text { eficácia do SGQ. }\end{array}$ & $\begin{array}{l}\text { Média da pontuação } \\
\text { das auditorias de } \\
\text { processo. }\end{array}$ & $\begin{array}{l}\text { Melhoria/Liderança } \\
\text {. }\end{array}$ \\
\hline $\begin{array}{l}\text { Comercial } \\
\text { devoluções }\end{array}$ & $\begin{array}{l}\text { Reduzir o número de } \\
\text { devoluções. }\end{array}$ & $\begin{array}{l}\text { \% de devoluções em } \\
\text { relação ao } \\
\text { faturamento. }\end{array}$ & $\begin{array}{l}\text { Abordagem por } \\
\text { processos. }\end{array}$ \\
\hline $\begin{array}{l}\text { Manutenção - } \\
\text { Quantidade de } \\
\text { manutenções } \\
\text { corretivas por } \\
\text { máquina }\end{array}$ & $\begin{array}{l}\text { Melhoria de máquinas e } \\
\text { equipamentos }\end{array}$ & $\begin{array}{l}\text { Quantidade de } \\
\text { manutenções por } \\
\text { máquinas realizadas } \\
\text { no mês }\end{array}$ & Melhoria. \\
\hline PCP - produção & $\begin{array}{l}\text { Atender as necessidades } \\
\text { dos nossos clientes. }\end{array}$ & $\begin{array}{l}\text { \% de produção com } \\
\text { relação ao total } \\
\text { vendido. }\end{array}$ & Foco no Cliente. \\
\hline
\end{tabular}

Fonte: Elaborado pelos autores (2021)

\section{CONCLUSÃO}

Este trabalho teve como objetivo fazer uma análise do sistema de medição de desempenho de uma empresa do setor agroindustrial quanto às etapas de desenvolvimento, implantação e uso. A organização teve um crescimento representativo nos últimos anos, 


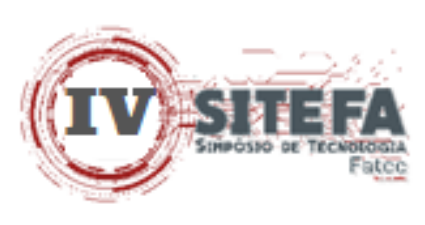

passando por processos de melhorias em sua gestão, porém ainda em relação à questão de controle precisa de alguns ajustes para ter um melhor monitoramento e desta maneira, alcançar seus objetivos.

A empresa em questão possui um SMD criado apenas para atender as normas da ISO 9001:2008 e apesar desta certificação ampliar o mercado de atuação e assegurar a qualidade perante os clientes, a necessidade de medidas de desempenho e a criação de indicadores exclusivamente para atendimento aos requisitos da norma, acabam restringindo o processo de desenvolvimento dos SMD, resultando na construção de indicadores de forma restrita e comprometendo o sucesso do desempenho organizacional.

A implantação do SMD foi feita de maneira mal esclarecida, e restrita apenas para responder questões impostas pelos indicadores do SGQ. O sistema de implantação encontrase deficiente, pois possui muitas falhas na sua comunicação, falta de divulgação de seus coordenadores para seus subordinados, a maioria dos funcionários da empresa nem sabem que existe esse sistema e muito menos da sua finalidade e importância para o desenvolvimento da empresa. Para os colaboradores que tem acesso, esses limitam sua finalidade para o alcance da certificação da ISO 9001:2008. Uma implantação com falhas pode comprometer inteiramente a estratégia determinada e todo o seu desempenho. Constatando-se na implantação dados mal apresentados, pouco esclarecidos, pobremente assimilados e quase ignorados por gerentes e colaboradores.

Como consequência de uma má implantação, o uso do SMD encontra-se restrito pelas áreas pela falta de esclarecimento dos seus benefícios, mostrando o quanto ele pode ser utilizado de maneira estratégica e não só apenas como respostas para atendimentos dos indicadores solicitados pela ISO 9001:2008. Esse estudo é interessante pelo fato de que a empresa em questão é a única que trabalha com o diferencial do cobre em sua formulação, tornando-se referência no mercado de defensivos e fertilizantes.

Uma empresa bem estruturada, referência no mercado de defensivos e fertilizantes, que possui um SMD, tem toda a estrutura para que esse seja benéfico e traga bons resultados estratégicos para as tomadas de decisões da organização, porém não atingiram a eficiência. Verifica-se que a empresa possui o SMD, porém este só foi implantado para atendimento das normas da ISO 9001:2008, ficando limitado pelo SGQ, restringindo-se apenas a esse tipo de controle.

O sistema possui um desenvolvimento muito bom para o que está sendo proposto no momento e que vai de acordo com as exigências do SGQ, porém ocorreram falhas na implantação e consequentemente o mal-uso do sistema. Tornando-se um sistema que atende as necessidades específicas da empresa, mas que poderia ser muito mais explorado, trazendo várias vantagens para a organização.

Em relação ao objetivo geral a empresa está mais bem estruturada no desenvolvimento, porém a maneira como o sistema foi implantado, não foi eficiente, não ficando claro e deixando o objetivo restrito apenas ao atendimento das normas ISO 9001:2008, e como consequência dessa má implantação, acabou influenciando o mal-uso dos sistemas que se encontra deficiente, apresentando várias dificuldades por parte dos envolvidos no processo.

O SMD da empresa mostrou restrito apenas a questão de controle no que se refere às rotinas e processos, sendo totalmente voltado para a Gestão da Qualidade da empresa, não sendo utilizado como uma visão estratégica.

Quanto às dificuldades do SMD foram na coleta de dados e registro; resistência e falta de importância dada pelos coordenadores; uso de indicadores inadequados; falta de uma 


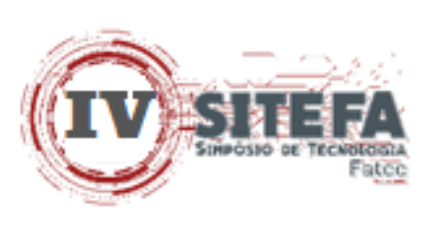

estruturação do sistema de indicadores; apenas um profissional, acúmulo de tarefas para o responsável pelo sistema, que é quem se encarrega da coordenação do sistema.

A empresa possui potencial para ter um SMD que possa ser mais bem aproveitado pelos gestores na sua tomada de decisão, porém deve melhorar a eficácia do seu sistema de implantação e uso. É necessário que o uso de indicadores possa integrar o SMD com o SGQ, de uma forma, porém, diferente de como é feito ainda hoje, em que uma lista de indicadores é geralmente proposta pela empresa que presta consultoria na implantação do SGQ, sem que tal conjunto de indicadores reflita as necessidades e a realidade da organização.

O SMD deve ser integrado e buscar comunicar sua posição e progresso influenciando

o comportamento e ações dos colaboradores da organização, fornecendo orientações suficientes para a sua gestão. Buscando por meio de uma cultura organizacional forte, desenvolver um bom desempenho, apresentando assim, estratégias bem-sucedidas.

Embora as medidas de desempenho dentro da organização apresentem grande importância dentro da organização, deve-se ter em mente que as medidas isoladas, geralmente não são capazes de fornecer informações suficientes para a tomada de decisão, devendo estar agrupadas, formando um sistema coeso e balanceado capaz de avaliar a eficiência e a eficácia do processo.

A empresa deve definir melhor os seus indicadores, expandindo para outras áreas, explorando melhor os seus resultados e serem claras na sua definição e alcance dos objetivos. É importante destacar que esta pesquisa de campo não permite generalizações por ser voltado somente para a empresa em questão.

\section{REFERÊNCIAS}

ASSOCIAÇÃO BRASILEIRA DO AGRONEGÓCIO (ABAG). Contribuição da agropecuária para o PIB brasileiro. 2021. Disponível em: https://abag.com.br/contribuicaoda-agropecuaria-para-o-pib-brasileiro/. Acesso em: 22 mar. 2021.

ATTADIA, L. C. D. L.; MARTINS, R. A. Medição de desempenho como base para evolução da melhoria contínua. Prod., São Paulo, v. 13, n. 2, p. 33-41, 2003. Disponível em: http://www.scielo.br/scielo.php?script=sci_arttext\&pid=S010365132003000200004\&lng=en $\&$ nrm=iso. Acesso em: 22 out. 2017.

CALLADO, A. L. C.; ANDRADE, L. P. Padrões utilizados de indicadores de desempenho não financeiros: um estudo exploratório nas empresas de Serra Talhada/PE. ABCustos Associação Brasileira de Custos, 2008. 3 (2), 1-23.

COOPER, D.; SCHINDLER, P. Métodos de pesquisa em administração. 7. ed., Porto Alegre: Bookman. 2003.

FACHIN, O. Fundamentos de Metodologia. 5. ed. São Paulo: Saraiva, 2006. 210 p.

FERNANDES, D. R. Uma contribuição sobre a construção de indicadores e sua importância para a gestão empresarial. Revista FAE, Curitiba, v. 7, n. 1, p. 1-18, jan./jun., 2004. 


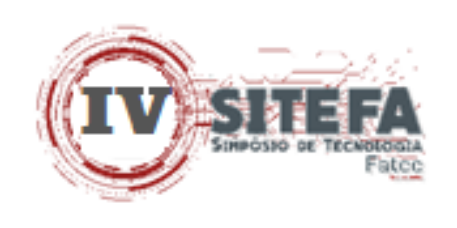

FUNDAÇÃO NACIONAL DA QUALIDADE (FNQ). Gestão da pequena empresa. Gestão na Pequena Empresa. 2012. Disponível em http://www.fnq.org.br/informe-se/artigoseentrevistas/artigos/gestao-na-pequena-empresa. Acesso em: 10 fev. 2021.

FRANCO-SANTOS, M.; KENNERLY, M.; MICHELI, P.; MARTINEZ, V.; MASON, S.; MARR, B.; GRAY, D.; NEELY, A. Towards a definition of business performance measurement systems. International Journal of Operations \& Production Management, v. 27, n. 8 , p. $784-801,2007$.

GUNASEKARAN, A.; PATEL, C.; TIRTIROGLU, E. Performance measures and metrics in a Supply chain environment. International Journal of Operations \& Production Management, v. 21, n. 1/2, p. 71-87, 2001.

KENNERLEY, M.; NEELY, A.; ADAMS, C. Survival of the fittest: measuring performance in a changing business environment. Measuring Business Excellence, Bradford, v. 7, n. 4, p. 37-43, 2003.

KUENG, P.; MEIER, A.; WETTSTEIN, T. Computer-based performance measurement in SMEs: Is there any option? Switzerland: University of Fribourg, Institute of Informatics. Internal Working Paper, n. 00-11, p. 1-15, 2000.

MITCHELL, G. Problems and Fundamentals of sustainable development indicators, 2004.

MIURA, K.; KOBAYASHI, N.; SHIRASAKA, S. A strategic performance indicator deriving framework for evaluating organizational change. Review of Integrative Business and Economics Research, v. 9, n. 4, p. 36-46, 2020.

NEELY, A.; AUSTIN, R. Measuring performance: The operations perspective. Business performance measurement: Theory and practice, p. 41-50, 2002.

OLIVEIRA, M.; LANTELME, E. M. V.; FORMOSO, C. T. Sistema de indicadores de qualidade e produtividade na construção civil: manual de utilização. Porto Alegre: SEBRAE, 1995.

SANTOS, E. A. D. Capacidade tecnológica e inovação em empresas de base tecnológica. Tese. Universidade Federal de São Carlos. 2020. Disponível em: https://repositorio.ufscar.br/handle/ufscar/13518. Acesso em: 10 fev. 2021.

SALOMON, D. V. Como fazer uma monografia. 2. ed. São Paulo: Martins Fontes, 1991. 